\section{Looking Forward}

\section{A statement by Maurice Jacob on being elected President of EPS}

\author{
I cannot grow \\ I have no shadow \\ To run away from. \\ I only play
}

\author{
W.H. Anden, Hymn to St. Cecilia (Britten)
}

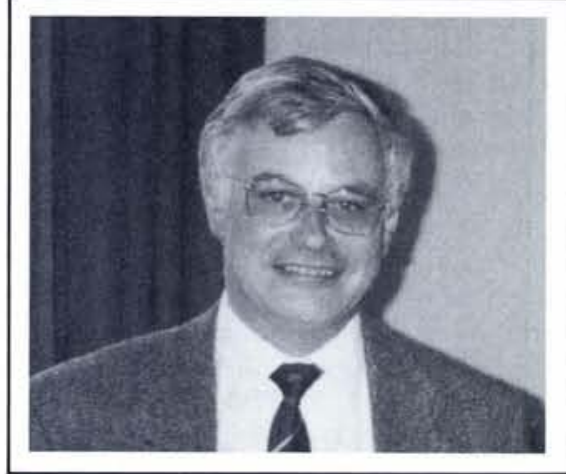

We have problems but we can grow. However the key question which we so often hear is: "Why should I join the EPS?".

This question actually covers two deeper questions, namely "What would the EPS do for me?", and "What is the EPS actually doing?"' - the latter probably being the more important of the two. The EPS does not yet have the visibility we would like to see associated with a thriving Society. Within the physics community at large, its name does not always immediately bring to mind proposals, activities and specific actions which clearly bear witness to its presence on the European scene.

I feel it my duty to present some still complicated answers to these simple questions. We, of course, all have some answers. The problem is that, despite them, the questions remain very much present.

I appreciated the positive vote in Council in favour of raising the unit fee. It recognizes the efforts made since the 1990 Council, and offers encouragement to continue the work. Council has also strongly expressed its wish for some important restructuring. The goal is clear. All physicists in Europe should find it natural to be affiliated with the EPS. Ways to achieve this have still to be found. The question should be addressed with a renewed energy. As clearly summarized during Council, our Society should be strong in the eyes of physicists. It should also be strong outside physics, and recognized as the natural partner by national and international organizations when considering physics in Europe.

\section{EPS on the European Scene Hang together}

Becoming a member of a physical society reflects a wish to be associated in a common endeavor bearing directly on our scientific interests. Membership also often translates into a willingness to become more personally involved in activities upon which physics thrives. Physicists do not work in isolation: their research implies a network of conferences, workshops and committees in addition to extensive discussions among themselves and with funding agencies. Whilst they often work in specialized areas having their own styles, structures and organizations, most are deeply sensitive to the great unity of physics. More than a profession, physics represents a way to look at the world and address profound issues using approaches extending beyond any obvious subfield and any national or cultural boundaries.

There is clearly a need for a broad approach to all questions associated with the development of physics as it forms a part of human culture and is a key element of our technological society. It should most clearly be met by a physical society. We all know that research has to progress on a wide front, and that harmony should prevail between the different domains of physics. As Benjamin Franklin once said: "Let us hang together or we shall hang separately".

\section{Defining a role}

The need for physicists to organize themselves, to work together, and to speak with one voice, is certainly at the origin of the great success of some national societies in Europe, notably those whose membership includes most of their country's physicists. However, in other countries, a more individualistic attitude still seems to prevail, and society memberships include but a limited fraction of the total number of physicists. This does not mean that the majority of physicists are satisfied with a relative isolation. Physical societies are not the only structures available. There also exist important authorities which often act as nation-wide organizations for research, speaking for physics at a government level, allocating funding and responding to specific initiatives. The development of these highly structured organizations, which complement the universities, arose from the growing importance of physics research. The increasing internationalisation of physics research also led to many links between national agencies and to the emergence of international organizations.

Being associated with one of these organizations may be considered enough, and all the more so as this does not imply a fee. Physical societies have had to define their role with respect to them. They do this with varying success.

There is a need for channels, running in parallel with such important and efficient structures, which respond to the grassroot support for new initiatives, and to questions and problems that are felt deep inside the physics community. These channels should operate independently of those offered by the official organizations, with their hierarchies and specific interests. Physicists should be able to express themselves and organize their collaboration independently of the often specialized and hierarchical structures to which they often also belong. National societies respond to that need, but with very different membership successes.

\section{Pan-European}

While physicists have always been keen to cooperate across national boundaries, they are now forced more and more by the evolution of their technical fields to conduct research in an international way. In areas where this is already well established, they have long realized how fruitful it can be. There should therefore be a feeling spreading among physicists in Europe that they belong to a European-sized community which expresses itself directly through EPS.

Being associated to a European-sized organization is certainly part of the motivation to become an IOM. There is even a "European dream" aspect, that is, a willingness to use physics to build a Europe which would eventually extend beyond the present achievements of the European Community, or even the wider circle of the some European research organizations.

\section{Professional appeal}

We have to acknowledge, unfortunately, that the number of IOM's is still relatively small. The European dimension of our community is not yet widely perceived at the individual level. There is an interesting point to notice in this context. In countries where national societies attract most of the active physicists, the motivation to also join the EPS is not yet present on a wide scale. On the other hand, in countries where national societies recruit a relatively small fraction of the physicists, their members are far more likely to also 
become IOM's. There is, for them, in joining their national society a strong vocational component, besides the purely professional one. It then easily extends to the EPS. The EPS should better respond to the hopes of those who join it with a European vocation by also becoming an invaluable professional tool. It should gain a visibility such that it is also clearly appeals to those who join a national society to first manifest their professional affiliation.

\section{Complementarity}

There is much to be done. But there is hope for success. Here comes another fact. In domains where European collaboration is already almost complete, the EPS is also very much present. Indeed, in view of structures for cooperation such as CERN and ECFA, one may wonder whether there is still room for the EPS! But one remarks that it is those physicists who apparently need the EPS the least who in fact use it to the full.

The reason may be that they already have experience in collaborating at the European level so they can use efficiently the extra and special possibilities offered by EPS. As an example, the very successful European High Energy Conference series started independently of the EPS back in 1961. Yet it eventually became natural that it should continue within the EPS, as it has done for many years. Similarly, CERN provides a very efficient structure and yet the HEPP Division is particularly active.

EPS thus complements existing European structures. In other domains, where European collaboration is far less advanced, the Society already provides some of the needed links. It has made its mark in running successful conferences and providing forums for discussion. This is especially important in areas where the use of international facilities, each serving a large number of users, is set to increase. Decisions to proceed with new facilities will rely more and more on the existence of a clear constituency of potential users. The EPS undoubtedly has a great role to play in helping them manifest themselves. It can provide the framework and legitimacy for the organization of meetings where discussions and assessments should first take place.

EPS has thus a important part to play through its speciality Divisions, which represent the key component of its activities, and its committees, whose work allows the Society to speak for physics and physicists at the full European level. Success also has much to do with the national societies, which represent the other component of the Society's dual structure that makes EPS quite different from a mere federation of national societies. EPS should act in close association with its Member Societies, which represent the largest fraction of its present grass-root support.

\section{Physical Societies - Past and Present} Traditional benefits

In the past, a physical society was basically a learned society where members met to exchange research results and information. Each society was an island of specialized knowledge in a world which considered science as a particular intellectual exercise. As they grew, societies started publishing journals and running conferences. Membership meant recognition by one's peers, advantageous subscription to specialized journals and the access with a reduced fee to conferences, with, in some cases, the right to present a communication. Societies manifest their specific presence by a bulletin, award prizes, act as forums for topical discussions, make their views known and put them to action by initiating new ventures, either at the advisory level or at a more concrete and direct one

\section{Things of the past}

Whilst initially organized on regional or national levels, the different physical societies adapted with different successes to a rapidly changing situation. In Europe, the post-war period has been a particularly challenging.

Peer recognition and assessment take place through universities and research organizations far more than through physical societies. Physics has largely become a business. In Europe, commercial publishers adapted more quickly and efficiently than most societies to the changing scene of having to operate journals on an international basis. The prevailing culture, based upon cheap photocopying, high subscription prices and the desire to protect one's personal shelves from an overwhelming invasion, is such that subscriptions to scientific journals have practically become a library business. An inexpensive subscription is no longer an incentive to join a society.

The same applies to conference fees. There are so many conferences that one attends only those from which one is likely to benefit most. Once this drastic choice has been made, support from laboratories has become rather widespread. So reduced conference fees are no longer a strong incentive to join a society, and the more so now that there are many important conferences run outside the control of any physical society. The big general conferences, which have still remained more closely associated with physical societies, are increasingly shunned in favour of "stand alone" conferences and topical meetings or even workshops. It is clear that reduced subscription rates and conference fees, long seen as incentives to join a physical society, will soon belong to the past.

\section{Opportunities}

The very same reasons which push these advantages into obsolescence, pro- vide, however, more strength to those incentives associated with being part of a society which has a recognized advisory role, and plays an active part in matters relevant to the life and evolution of research and of advanced teaching in physics. It is therefore in these directions that EPS should develop its activities. Our Divisions and Interdivisional Groups should respond even more quickly and efficiently to precise needs in their fields, so that their actions can be clearly perceived within their research communities. Our Action Committees should expand their activities as forums for discussion and as the originators of specific advice and actions, so that the European physics community at large sees there is a powerful way to make itself heard.

A modern physical society thus has three important roles to play:

- It should contribute to the development of research though its advisory role with funding agencies and through the organization of conferences and meetings. - It should foster a better synergy between pure research and industry, for a sharp dichotomy between pure and applied research has many disadvantages. - It should help in making choices for the formation of physicists and for a better appreciation of physics research by the public at large.

The main advantage the EPS can offer its members must be the possibility to play an active part in a thriving hub of activities which meets these three requirements at the European level. The Society should provide a frequently used base for those interested in launching new activities. Some of our recent initiatives, reported in Europhysics News, stand as useful examples.

\section{Some examples}

My past experience with the French Physical Society gives me confidence that a society, despite, but rather because of, its lack of executive power, is listened to. Deciders like to hear from an independent forum, and they also appreciate funding a sounding board for new proposals which responds independently of any of the existing and powerful hierarchies through which they manage research.

The life of the Society has to also find direct and easily accessible expression through its bulletin, which should be deemed worth reading. Europhysics News has improved, in particular in its coverage of topical questions. It will be possible to develop further, even in the present framework of adiabatic expansion.

The Society met success with Europhysics Letters. However, the publishing market in Europe is largely in the hands of efficient commercial publishers and as we lack capital there is little that one can do at present on the purely publishing side. This is sad since this is a most natural 
source of income for physical societies. Given the present trend to "farm out", it is perhaps not even clear that we should try to expand in this area. Nevertheless, much more can be done in participating at the editorial level in existing and future physics journals.

\section{Where to Act}

The EPS is a society of societies as well as a society of members. Seen from the individual's point of view, this is often not very satisfactory and the question of the two separate memberships which it implies has been repeatedly addressed. Questions also repeatedly come from both components of our dual structure. Some national societies would like to consider the EPS as a federation of societies, with membership of a national society coming first and implying direct membership in EPS.

However, some Divisions which organize very successful EPS conferences and workshops are annoyed to see that only a few participants are IOM's. Most participants appear satisfied with membership in a national society, or, actually, with no membership at all. Special fees have, as we saw, a declining incentive value: there is no point playing too much on them. The Division Boards would like to see only one kind of membership, but which would then be an EPS one to start with, since it would be linked to a specialized Division activity in the first place. The hope is that a sizable increase in EPS membership could then snowball. From this point of view, national societies would then appear as "national groups" within the wider structure provided by EPS.

The question is difficult since the unique membership solution appears quite different when approached from one or the other of the two components of our dual structure. But they both raise it so the question has definitely to be addressed. There is clearly a mandate from Council so it will be the main item on the agenda of the Executive Committee. It is our hope to approach the national societies and the Divisions with proposals in time for a discussion at Council, in Athens, next March.

The EPS should also provide closer links with physics in the world at large. The Society should, in particular, have stronger specific and privileged links with the American Physical Society and with the newly created Association of Asian Pacific Physical Societies. These links, especially with the former, would become more lively if they directly involved the Divisions. The aim then would be to better coordinate the organization of conferences and to run topical joint workshops. Much remains to be done. The interest expressed by Council was clear. It is our hope to implement initiatives as quickly as possible. Associations with other large physical societies in the world, who consider the EPS as their natural partner in Europe, should be a further incentive to join the EPS once their outcome has become lively and visible to all.

We should develop our links with our Associate Members into an active partnership. They represent a most valuable connection with applied research and industry. They certainly represent part of the solution to our financial problems.

As Benjamin Franklin wrote in The Way of Wealth, reprinted 400 times: "There is no gains without pains. If we are industrious we shall never starve; at the working man's house, hunger looks in but does not enter, nor will the bailiff or the constable enter, for industry pays debts while despair increases them". Let us work together for a brilliant 25th Anniversary of EPS in 1993.

\section{EUROPEAN RESEARCH CONFERENCES A Pragmatic Approach}

The European Science Foundation (ESF) launched in 1990 a series of meetings called the European Research Conferences (ERC). The programme is managed by the ESF and supervised by an ESF steering committee.

The EPS as a learned society was invited by the ESF to appoint a member to the steering committee to check and guarantee the quality of ERC's in physics. All conferences covering a physics topic must be approved by a working group of EPS composed of several members of the Action Committee on Conferences.

\section{Organization of ERC's}

A Chairman responsible for the scientific programme has available about 20000 ECU to invite speakers and preferentially support the participation of younger scientists. This amount is allocated by the ESF and funded by the European Community (EC). The number of participants at an ERC should in general not exceed about 100 to guarantee lively discussion of scientific topics which are not yet ready for publication. Proceedings will therefore in general not be published.

It is intended that conferences be held as a series with an annual or biannual sequence. The Chairman of a succeeding conference should be elected early enough so that he or she can act as the Vice-Chairman of the current meeting.

ERC's should take place at locations where the participants can live together for the duration of the conference to allow for discussion outside the technical sessions. Locations will generally be proposed by the ESF steering committee based in Strasbourg, which also will be responsible for administration. Organizational arrangements are intended to ensure that the Chairman of the conference is relieved of administrative work. This implies, however, that the ESF office determines the conference fee.

Seed money from the ESF in addition to the usual conference fees was used to start the ERC's in 1990 and 1991. It was expected that funding support from the EC would start in 1991 but the necessary decisions have been postponed to September 1991. This may cause some difficulties in pursuing the published programme.

\section{Programme}

Two ERC's covering physics topics were held in 1990, the first year of the programme. The 1991 programme in physics was approved by the EPS Working Group in December 1990 and it comprises six conferences (see Europhysics News, Meetings Issue, March 1991).

The 1992 programme which is presently being discussed will include about eight ERC's in physics. Proposals for these conferences mostly came from EPS divisions. ERC's thus follow along the same lines as the well established Study Conferences.

\section{Further Developments}

The ERC scheme seemed almost ideal when it started, leading to the suggestion that the Europhysics Study Conferences may merge completely into the ERC's. However, in the course of establishing the ERC's and developing the rules which should guide the conferences and negotiations with the Commission of the EC (CEC), several restrictions became apparent.

EPS incorporates Divisions having research goals that are different from the pure science, such as educational development, the history of physics and scientific matters that are not strictly in physics but are nonetheless closely connected. Conferences organized by these Divisions had to be excluded from the ERC scheme because the topics did not fit into the guidelines set out by the CEC for supporting ERC's.

Furthermore, the Divisions of EPS have considerable experience in organizing conferences so in many respects they do not need the close help of the ESF. This led to serious discussions and finally to the withdrawal of one conference from the ERC schedule for 1992. Points of discussion were site selection, conference fees and, in some cases, interference in inviting speakers.

The EPS Conference Committee will thus adopt a pragmatic approach in future. If conferences can be included in the ERC scheme we shall do this wherever possible and try to obtain the financial support of ESF. In some cases, the Divisions may, however, wish to proceed as in the past and organize Study Conferences following the well established guidelines.

\section{K. Bethge}

Chairman,

EPS Action Committee on Conferences 